\section{Autoantikörper gegen PML}

\author{
W. Stöcker \\ Euroimmun Medizinische Labordiagnostika AG, Lübeck, \\ Deutschland
}

Synonym(e) Anti-PML-Antikörper; Autoantikörper gegen promyelozytäre leukämische Proteine

Englischer Begriff autoantibodies to PML (promyelocytic leukemia antigen)

Definition Das PML-Antigen ist Bestandteil der ,promyelocytic leukemia nuclear bodies“ (PML-NB, Kerngranula).

Funktion - Pathophysiologie Bei etwa einem Drittel der Patienten mit primär biliärer Cholangitis ( $\mathrm{PBC}$, früher: Primär biliäre Zirrhose) können mittels indirekter Immunfluoreszenz Autoantikörper gegen Zellkerne (ANA) nachgewiesen werden. Während der vergangenen 10 Jahre konnten eine Anzahl von Kernstrukturen als spezifische ANA-Zielantigene bei PBC ermittelt werden. Diese umfassen promyelozytisch leukämische Proteine (PML-Proteine) und Sp100 sowie 2 Komponenten des Kernporenkomplexes (GP 210, s. > Autoantikörper gegen Glykoprotein 210, und p62).

\section{Untersuchungsmaterial Serum, Plasma.}

Probenstabilität Autoantikörper sind bei $+4{ }^{\circ} \mathrm{C}$ bis $\mathrm{zu}$ 2 Wochen lang beständig, bei $-20^{\circ} \mathrm{C}$ über Monate und Jahre hinweg.

Analytik Autoantikörper gegen PML können mittels indirekter Immunfluoreszenz ( $\triangleright$ Immunfluoreszenz, indirekte) nachgewiesen werden und ergeben ein Nuclear-dot-Muster. Eine exakte Bestimmung ist auch mit Linienblots
( $\triangleright$ Immunblot) oder einem $\triangleright$ Enzyme-linked Immunosorbent Assay unter Verwendung von rekombinantem PML möglich.

\section{Referenzbereich - Erwachsene Negativ.}

Indikation Primär biliäre Cholangitis (PBC) und kombinierte Lebererkrankung (Overlap-Syndrom).

Diagnostische Wertigkeit Autoantikörper gegen PML werden bei etwa $13 \%$ der Patienten mit PBC gefunden, treten aber auch bei $4 \%$ der Patienten mit Autoimmunhepatitis (AIH) auf. Diese Antikörper werden zusätzlich vereinzelt in Seren von Patienten mit Virus-induzierter Hepatitis B und $\mathrm{C}$ beobachtet.

Die gemeinsame Bestimmung der Autoantikörper gegen PML, SP100, GP 210, AMA-M2 und M2-3E erhöht die diagnostische Sensitivität für PBC auf $94 \%$ bei einer Spezifität von $99 \%$ und dient der Abgrenzung gegenüber anderen autoimmunen Lebererkrankungen; s. a. P PBC-assoziierte antinukleäre Autoantikörper.

\section{Literatur}

Invernizzi P, Selmi C, Ranftler C, Podda M, Wesierska-Gadek J (2005) Antinuclear antibodies in primary biliary cirrhosis. Semin Liver Dis 25:298-310

Mytilinaiou MG, Meyer W, Scheper T, Rigopoulou EI, Probst C, Koutsoumpas AL, Abeles D, Burroughs AK, Komorowski L, Vergani D, Bogdanos DP (2012) Diagnsotic and clinical utility of antibodies against the nuclear body promyelocytic leukaemia and Sp100 antigens in patients with primary biliary cirrhosis. Clin Chim Acta 413:1211-1216

Sternsdorf T, Guldner HH, Szostecki C, Grotzinger T, Will H (1995) Two nuclear dot-associated proteins, PML and Sp100, are often co-autoimmunogenic in patients with primary biliary cirrhosis. Scand J Immunol 42:257-268

Szostecki C, Guldner HH, Will H (1997) Autoantibodies against „nuclear dots“ in primary biliary cirrhosis. Semin Liver Dis 17:71-78 